\title{
INVESTIGATION OF USING LOW COST MEMBRANES IN DIALYSIS PROCESSES
}

\author{
Y.S. Fangary
}

Mechanical power eng. department, Faculty of Eng., Ain Shams University, Cairo - Egypt

Received 29 October 2013; revised 23 November; accepted 31 November 2013

\section{ABSTRACT}

In the present work dialysis process was examined using two types of easily available low cost membranes; nylon and polyethylene. The mass transfer through the membranes was affected by the flow rate of solutions passing by the membrane in parallel flow but with no consistent pattern. The overall mass transfer coefficient of the membranes was less by 10 times than that published by other authors for commonly used membranes in dialysis processes. A correlation was developed to predict the mass transfer coefficient and when compared with experimental data showed acceptable agreement.

keywords: dialysis, mass transfer, membranes,separation

\section{Introduction}

Dialysis is a process for transport of molecules through the membrane by concentration difference between two solutions at both sides of the membrane. The famous applications of dialysis are hemo-dialysis for removing the metabolic waste from blood and the recovery of acids from various waste solutions by employing ion-exchange membranes.

The performance of dialysis can be improved significantly by the effect of ultrafiltration. Ultrafiltration is the process driven by tansmembrane pressure for the concentrate of macromolecular solution or the recovery of valuable constituents.

Yeh et al. (1997) presented an analytical solution of solute concentration for the systems of dialysis coupled with ultrafiltration in cross flow membrane modules using the method of perturbation, therefore the separation efficiencies could be calculated for various operating and design conditions.The model depends on the solution of the partial differential equations for solute concentration distribution in retenetate (salt solution) and dialysate (water) phases that were derived based on mass balances. Then the concentration distributions were determined by the method of perturbation with consideration of uniform permeate flux.

They found that for the operation of absorption or extraction in the membrane contactors the mass transfer coefficient in cross flow modules is at least two times more than that in parallel flow module. Also it was found that increasing the flow rate in retenetate phase is more beneficial to the mass transfer than increasing the flow rate in dialysate phase. Also the rate of solute removal decreases sharply with increasing solute molecular weight.

Raff et al. (2003) proposed another model for high flux hemodialysis coupled with ultrafiltration. They proposed a model to calculate the rate of hemodialysis based on a set of equations that can be solved using the standard Mathcad software. They proposed that good performance of high flux dialysers means high clearance of molecules at low ultrafiltration levels. Their model showed good agreement between the predictions and available experimental data.The main finding of their study was that the model showed that after a certain length of the dialyser inversion process occurs. Also the results showed that dialysis process is slightly affected by increasing ultrafiltration rates. 
Yeh and Chang (2005) carried out a study on membrane dialysis in parallel plate rectangular mass exchangers under co-current and counter current flow operations. It was found that mass transfer of dialysis in rectangular mass exchangers of microporous membrane can be analogous to heat transfer in rectangular heat exchangers. They found that the separation efficiency increased with the increase in flow rate of the retenetate phase or the increase of the flow rate of dialysate phase or with the ratio of the flow rate of dialysate phase to the retenetate phase.They proposed a simple model to calculate the mass transfer in rectangular dialysers.

Palaty et al. (2006) elaborated a simple and reliable procedure for the calculation of the basic transport characteristics of membrane/solution systems when variable liquids flow rate along the membrane exists. They proposed a model based on the numerical integration of the set of ordinary differential equations describing the concentration dependency of the component dialysed in both compartments upon the height co-ordinate. The model used takes into account a variable flow of liquid along the membrane as a consequence of the solvent transport through the membrane. The model showed that the overall dialysis coefficient is insensitive to the volume flow rate and that the membrane coefficient varied inversely with acid (used in their experiments) concentration.

Alkan-Sungur and Ozdural (2009) proposed a model to predict the mass transfer coefficient for aqueous salt solutions. The model showed that the overall mass transfer coefficient increases with increase of the flow rate due to the decrease of concentrate size film i.e. mass transfer resistance.

\section{Experimental work}

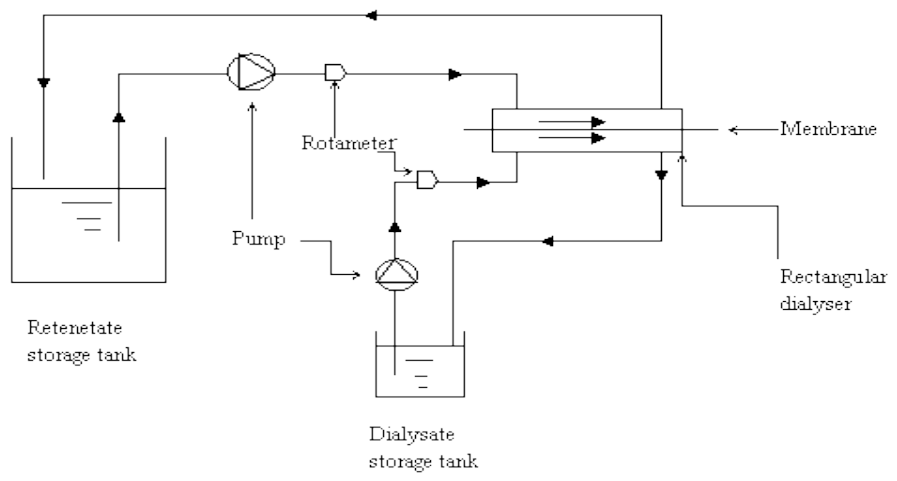

Fig. 1. Schematic and flow diagram of the test rig.

The test rig used in present work, shown in Fig. (1), consists of a rectangular dialyser. The dialyser consists of two chambers separated by a membrane. The dimensions of each chamber is $\mathrm{L} \times \mathrm{W} \times \mathrm{h}=0.18 \times 0.115 \times 0.004 \mathrm{~m}$.

The dialysate (tap water) and retenetate(aqueous sodium chloride solution) flow via two separate diaghragm pumps. The flow of each is in a closed loop where the storage tank of the dialysate is of volume 0.5 liter where that of the retenetate is 3 liter. Due to the large volume of the retenetate storage tank the concentration of salt in it was found to be nearly unchanged during the course of the experiments. Two types of membranes were used; commercial nylon membrane and commercial polyethelyne membrane (of estimated porosities $7 \%$ and $11 \%$ respectively). The thicknesses of the nylon and polyethelyne membranes are 15 and $52 \mu \mathrm{m}$, respectively. 
Experiments were carried on by allowing the flow of dialysate and retenetate at each side of the membrane then measuring the TDS (total dissolved solids in ppm) for the dialysate tank every $15 \mathrm{~min}$ over a period of one and half hour.The membrane was completely replaced after each run i.e. $1.5 \mathrm{hr}$.

The flow rate in both sides was adjusted at $0.1,0.125$ and $0.15 \mathrm{l} / \mathrm{min}$ (corresponding to $\mathrm{Re}=$ 218, 273 and 324, respectively) and all possible flow combinations in the two chambers were examined. The flow rate in both sides was measured using sensitive rotameters provided by RS company. The TDS was measured using a Hanna instruments meter.

\section{Experimental results and data analysis}

Figures (2a) and (2b) show the cumulative concentration in the dialysate over a period of 1.5 hrs at 15 minutes interval for the nylon and polyehelyne membranes respectively. Three sets of experiments were carried out at equal flow rates for each set $(0.1,0.125$ and $0.15 \mathrm{l} / \mathrm{min})$ of the dialysate and retenetate.The figures show that the mass transferred increases with time for the two membranes. From Fig. (2a) the results show that for the nylon membrane the mass transferred increases with time. The highest mass transfer was obtained at $0.125 \mathrm{l} / \mathrm{min}$. At the flow rate 0.15 $1 /$ min the mass transfer also increased with time through the whole period, but the rate of its increase began to decline and the total mass transferred became and continued to be the lowest compared to those at other flow rates at time beyond $45 \mathrm{~min}$. From Fig. (2b), polyethelyne membrane, it can be shown that increasing the flow rate increases the mass transferred except at $0.125 \mathrm{l} / \mathrm{min}$ where the lowest mass transfer was obtained.
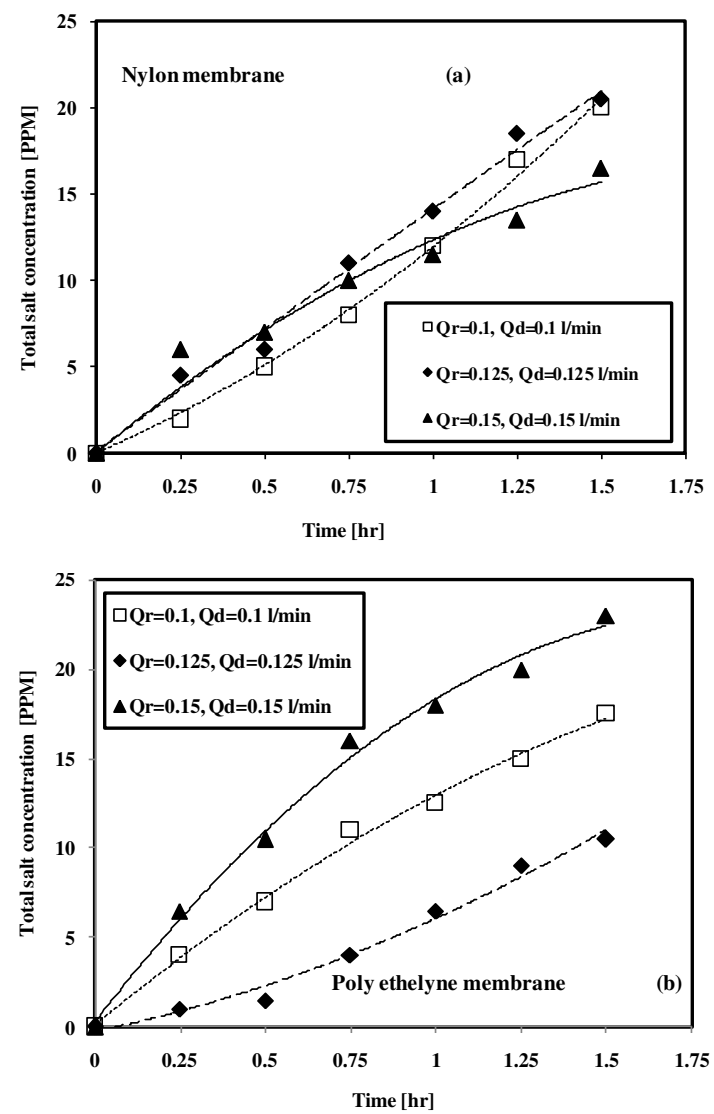

Fig. 2. Total concentration at intervals of 15 min over a time period of $1.5 \mathrm{hr}$. 
Figure (3) shows the cumulative concentration in the dialysate over a period of time 1.5 hrs at $15 \mathrm{~min}$ interval but in this case the flow rate of the retenetate was fixed at $0.1 \mathrm{l} / \mathrm{min}$ and the flow rate of the dialysate phase was varied. Figure (3a) shows the results for the nylon membrane from which it can be found that under such conditions increasing the dialysate flow rate increases the mass transfer of salts. Figure (3b) shows the results for polyethelyne membrane which gave opposite results to those in Fig. (3a) i.e. increasing the dialysate flow rate decreases the transferred mass of salts.
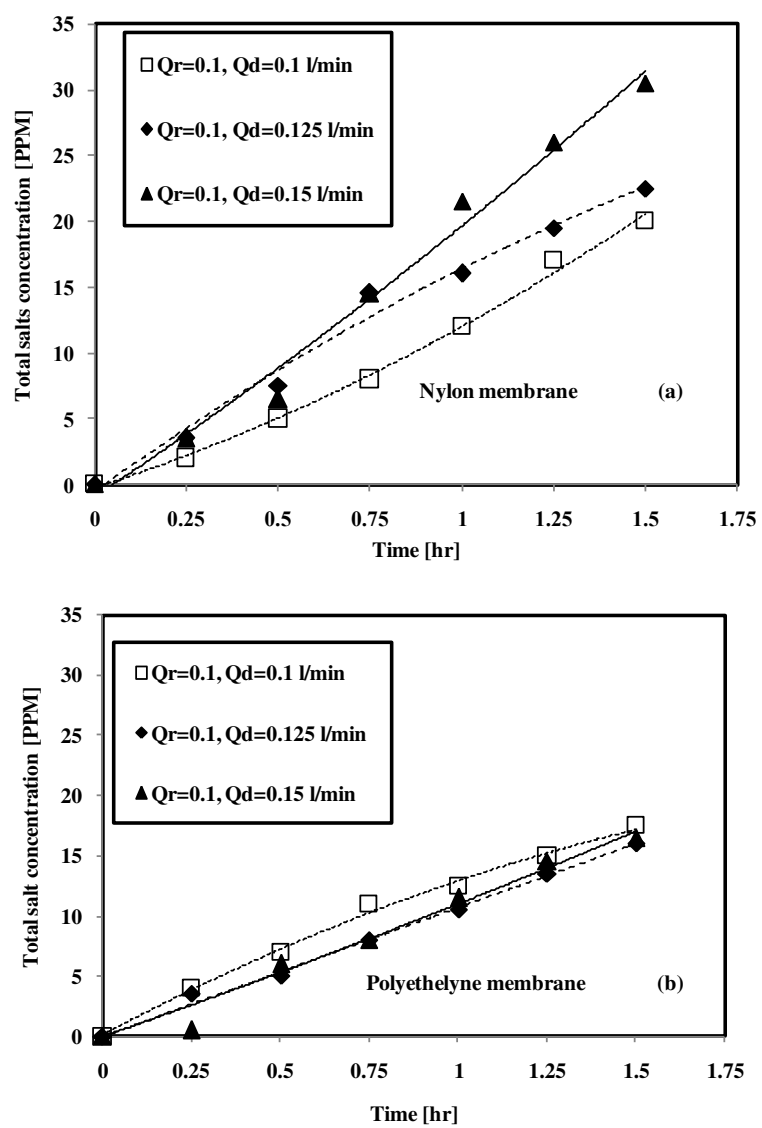

Fig. 3. Total concentration at intervals of 15 min over a time period of $1.5 \mathrm{hr}$.

Figure (4) shows the cumulative mass transferred in the dialysate over a period of time $1.5 \mathrm{hrs}$ at $15 \mathrm{~min}$ interval. In this case the retenetate flow rate was fixed at $0.125 \mathrm{l} / \mathrm{min}$ while the flow rate of the dialysate was varied. Figure (4a) shows the results for the nylon membrane from which it is clear that for such flow rate of the retenetate increasing the dialysate flow rate decreases the amount of mass transferred. For the results of the polyethelyne membrane,Fig. (4b) shows that under the same conditions minimum mass transferred is obtained when the dialysate flow rate was $0.125 \mathrm{l} / \mathrm{min}$. 

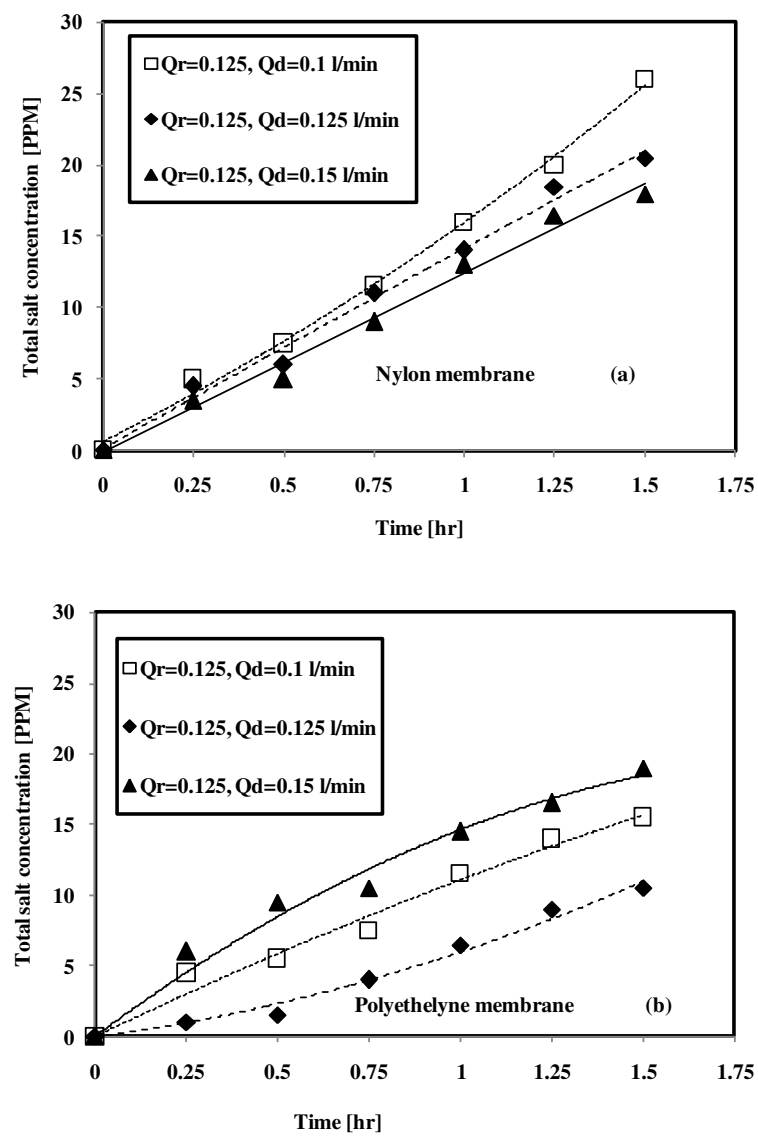

Fig. 4. Total concentration at intervals of 15 min over a time period of $1.5 \mathrm{hr}$.

Figure (5) shows also the cumulative mass transferred in the dialysate over a period of time $1.5 \mathrm{hrs}$ at $15 \mathrm{~min}$ interval for fixed flow rate of the retenetate at $0.15 \mathrm{l} / \mathrm{min}$, while varying the flow rate of the dialysate. From figure (5a) the results for the nylon membrane shows that under such conditions the variation of the cumulative mass transferred with the flow rate of the retenetate is low, it increases by its increase by approximately $7 \%$. Figure (5b) shows the results of the polyethylene membrane under the same conditions and the results showed that the minimum mass transferred was obtained at dialysate flow rate $\leq$ $0.125 \mathrm{l} / \mathrm{min}$. 

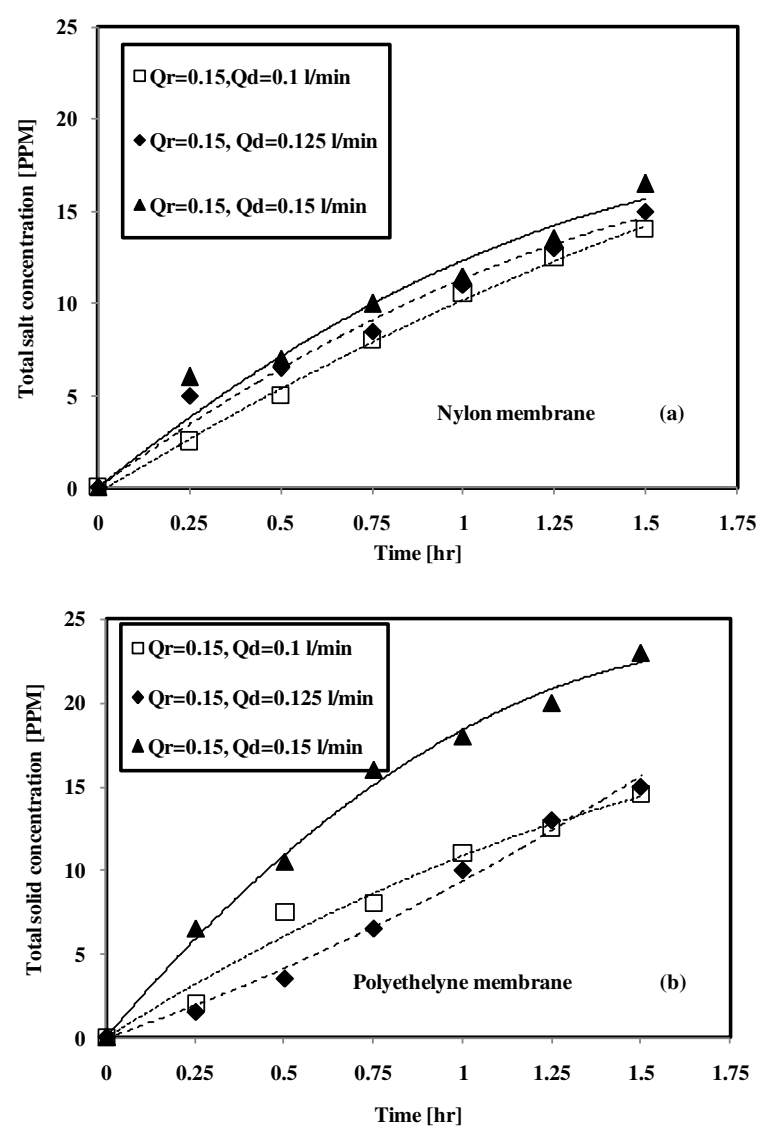

Fig. 5.Total concentration at intervals of 15 min over a time period of $1.5 \mathrm{hr}$.

In order to find which flow rate on either sides of the membrane is the dominant flow rate in mass transfer process figure(6) shows a comparison between two flow rates 0.1 and $0.125 \mathrm{l} / \mathrm{min}$ each interchangeably fixed at each side of the membrane. For thenylon membrane the results are shown in figure (6a) from which it can be seen that changing the velocities at different sides of the membrane has nearly no effect on mass transferred. Figure (6b) shows the same results for the polyethelyne membrane.

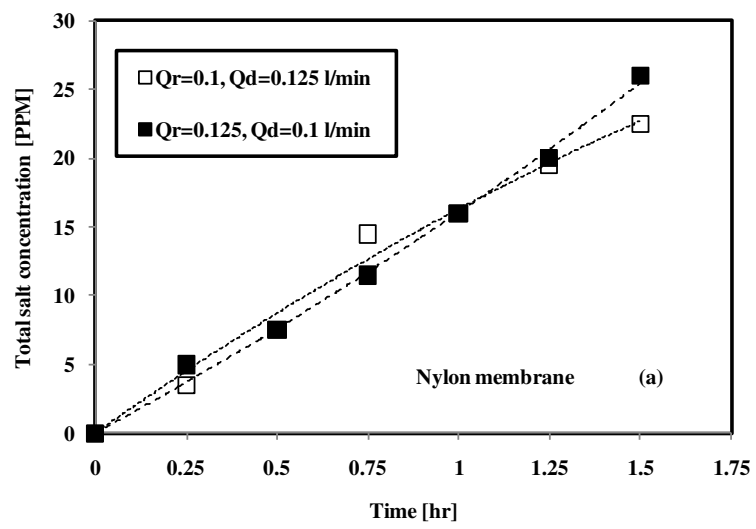




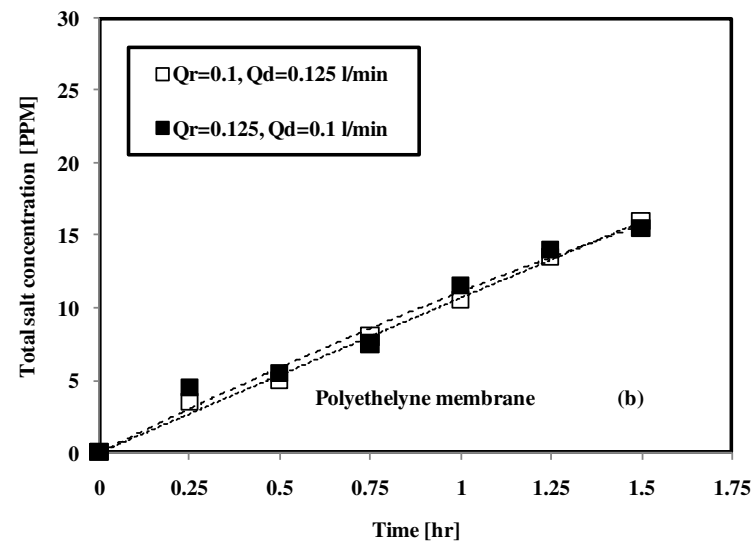

Fig. 6. Total concentration at intervals of 15 min over a time period of $1.5 \mathrm{hr}$.

The previous experiments werecarried out for another two flow rates 0.1 and $0.151 / \mathrm{min}$. Figure (7a) shows the results for the nylon membrane from which it is found that increasing the dialysate flow rate increases the mass transfer. Results for the polyethelyne membrane, Fig. (7b), shows that nearly no effect was noticed when the same experiments were repeated.
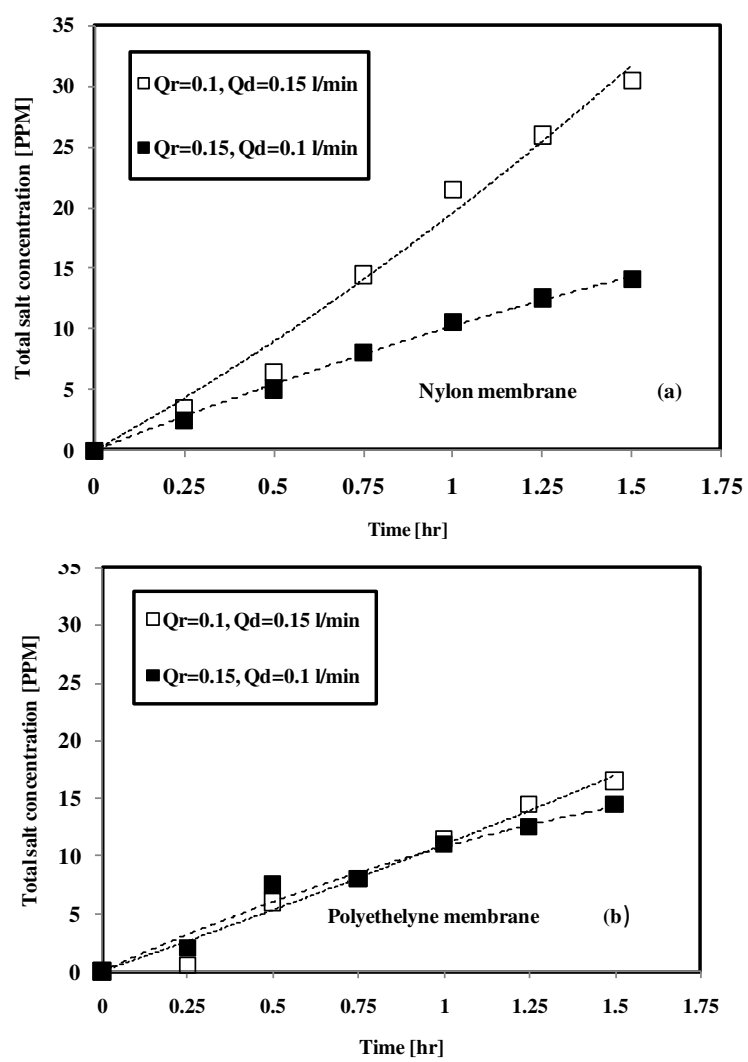

Fig. 7. Total concentration at intervals of 15 min over a time period of $1.5 \mathrm{hr}$.

\subsection{Comparison between the Performanceof the Two Membranes}

Figures. ( $8 \mathrm{a}, 8 \mathrm{~b}$ and $8 \mathrm{c})$ show a comparison between the mass transferred from the two membranes used in the present work at different flow rates (the dialysate and 
retenetateflow rates were the same) $0.1,0.125$ and $0.151 / \mathrm{min}$, respectively. At the lowest flow rate, 0.1 l $/ \mathrm{min}$, Fig.(8a) shows that the mass transferred from both membranes is very close. When the flow rate was increased to $0.125 \mathrm{l} / \mathrm{min}$ the nylon membrane has superior mass transfer capabilities than the polyethelyne membrane as can be seen from Fig. (8b). Further increase of the flow rate to $0.15 \mathrm{l} / \mathrm{min}$ shows that the polyethelyne membrane has superior capabilities regards mass transfer than the nylon membrane as can be seen from Fig. (8c).
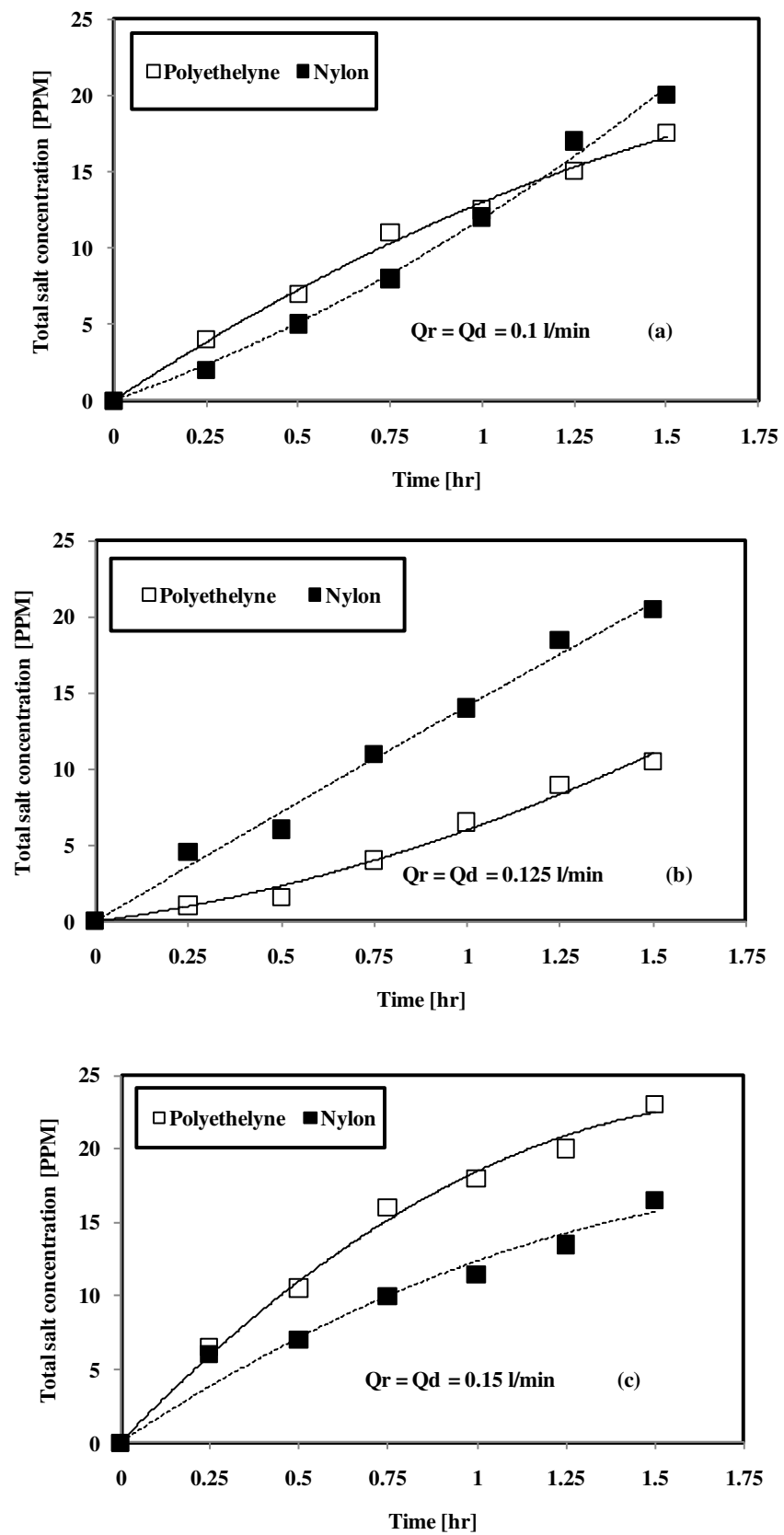

Fig. 8. Total concentration at intervals of 15 min over a time period of $1.5 \mathrm{hr}$. 


\subsection{Stability of mass transfer process through used membranes}

Since in most dialysis processes the stability of mass transfer process is important, Fig. (9) shows the amount of mass transferred between every measuring interval. From figure (9a) for the nylon membrane it is clear that the mass transferred fluctuates which is nearly the same for the polyethelyne membrane as seen in Fig. (9b).Further inspection of the results presented in Fig.(9a and 9b) shows that the fluctuations diminish after approximately one hour for the polyehelyne membrane and is expected to diminish for the nylon membrane after $1.5 \mathrm{hr}$.
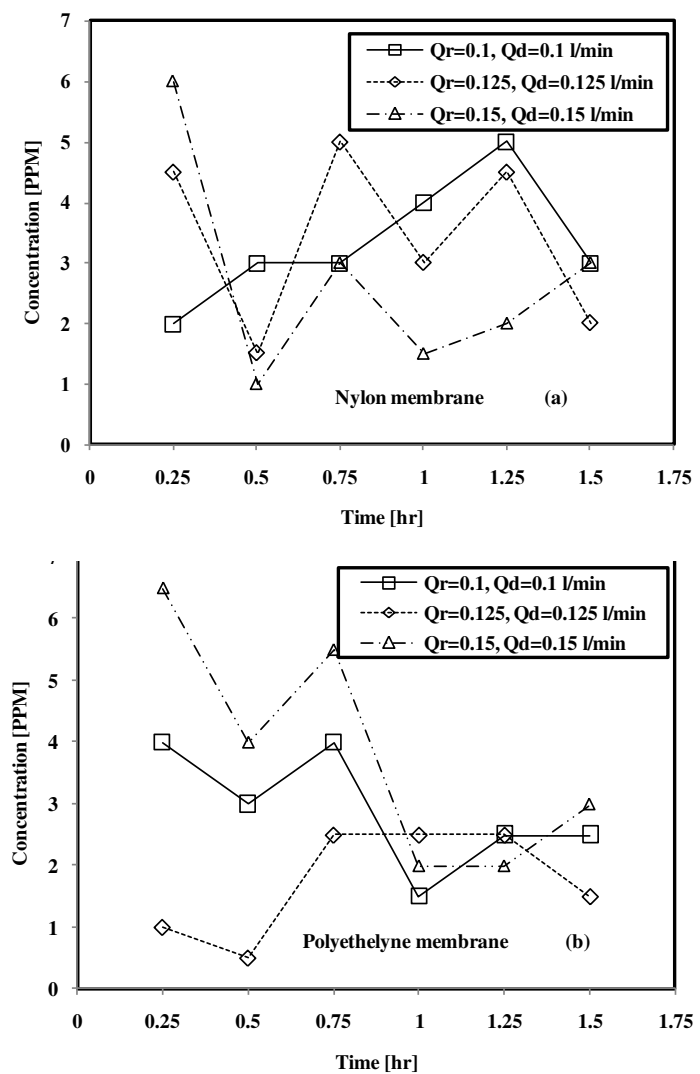

Fig. 9. Concentration at intervals of 15 min over a time period of $1.5 \mathrm{hr}$.

\subsection{Determining the overall transfer coefficient of the tested membranes}

It is of major importance to examine the overall membrane mass transfer coefficient and comparing the results with the data published for what we can call standard membranes. In order to do so the overall transfer coefficient was calculated from the following equation:

$$
M=K \rho_{d}\left(C_{r}-C_{d}\right)
$$

The data obtained was presented in Fig. (10) with the help of the key in the following table:

Table 1.

\begin{tabular}{|l|l|l|}
\hline Data point number & Retenetate flow rate & Dialysate flow rate \\
\hline 1 & 0.1 & 0.1 \\
\hline 2 & 0.125 & 0.125 \\
\hline 3 & 0.15 & 0.15 \\
\hline 4 & 0.1 & 0.125 \\
\hline
\end{tabular}


Y.S. Fangary

\begin{tabular}{|c|l|l|}
\hline Data point number & Retenetate flow rate & Dialysate flow rate \\
\hline 5 & 0.1 & 0.15 \\
\hline 6 & 0.125 & 0.1 \\
\hline 7 & 0.125 & 0.15 \\
\hline 8 & 0.15 & 0.1 \\
\hline 9 & 0.15 & 0.125 \\
\hline
\end{tabular}

Figure (10) shows the variation of the overall mass transfer coefficient with different flow rate combinations at the membrane sides. In general it is shown that the nylon membrane has higher overall mass transfer coefficient than the polyethelyne membrane. Best combinations are 4,5 and 6 (in the previous table) as shown from Fig. (10) were obtained usingthe nylon membrane.

The results in Fig. (10) show that $\mathrm{K}$ varied between $0.94 \times 10^{-7}-2.8 \times 10^{-7}$ which is approximately 10 times less than published data in the literature which approximately ranges between $1 \times 10^{-6}$ (Palaty et al. (2006) and Alkan-Sungur and Ozdural (2009)).

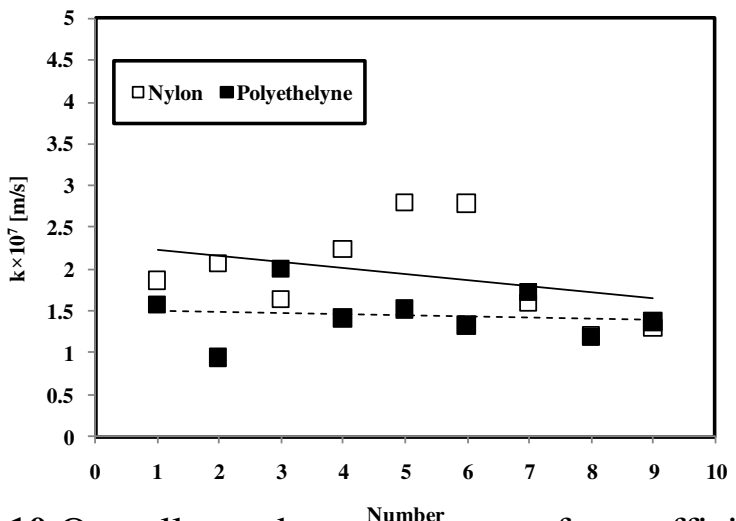

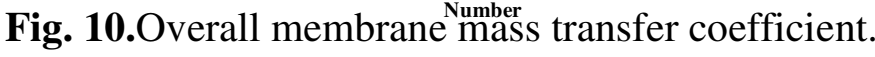

\subsection{A Correlation to predict overall mass transfer coefficient}

The followingcorrelation is developed to relate the actual mass transferred over a certain time period, flow rates and chamber dimensions:

$$
K=8 \times 10^{-4} \frac{Q_{d}{ }^{2}}{W L Q_{r}} \ln (\Delta C)^{\left[h W L /\left(Q_{d} t\right)\right]}
$$

Where $\Delta \mathrm{C}$ is the concentration difference during time period in PPM.

The correlation was compared with the experimental data as shown in Fig. (11) and acceptable agreement was found. 


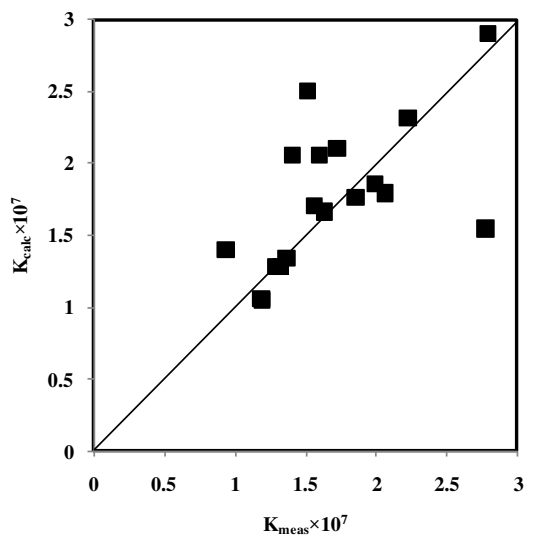

Fig. 11.Comparing measured $\mathrm{K}$ values with those calculated from correlation 2 .

\section{Conclusions}

In regard to their availability and low price the two examined membranes showed acceptable performance for transferring salts through them. The nylon membrane in general has higher overall mass transfer coefficient compared to that of the polyethelyne membrane. The mass transfer over a period of time if divided into equal intervals is not constant for both membranes and suffers from fluctuations.

There was no consistent pattern regards the increase or decrease of mass transferred through the examined membranes with flow rate at both sides of the membranes.

The overall mass transfer coefficient $\mathrm{K}$ is 10 times less than published membranes data.

A correlation was derived to predict the overall mass transfer and acceptable agreement between measured values and the correlation predicted values were found.

\section{Acknowledgment}

The author of the present work wouldlike to thank Prof. H.Barakat for revising the manuscript, also thanks to Dr. T. Hassan for carrying out the measurements of membranes thickness.

\section{Nomenclature}

\begin{tabular}{lll}
$\mathrm{C}_{\mathrm{d}}, \mathrm{C}_{\mathrm{r}}:$ & Concentration of respective phase & {$[\mathrm{ppm}]$} \\
$\mathrm{h}$ & Flow channel height & {$[\mathrm{m}]$} \\
$\mathrm{K}:$ & Overall membrane mass transfer coefficient & {$[\mathrm{m} / \mathrm{s}]$} \\
$\mathrm{L}:$ & Membrane length & {$[\mathrm{m}]$} \\
$\mathrm{M}:$ & Mass transfer rate per membrane area & {$\left[\mathrm{kg} / \mathrm{m}^{2} . \mathrm{s}\right]$} \\
$\mathrm{Q}_{\mathrm{d}}, \mathrm{Q}_{\mathrm{r}}:$ & Flow rate of the respective phase & {$\left[\mathrm{m}^{3} / \mathrm{s}\right]$} \\
$\mathrm{Re}:$ & Reynolds number & {$[-]$} \\
$\mathrm{t}:$ & time & {$[\mathrm{s}]$} \\
$\mathrm{W}:$ & Membrane width & {$[\mathrm{m}]$} \\
Greek symbols & & \\
\hline$\rho:$ & Density & {$\left[\mathrm{kg} / \mathrm{m}^{3}\right]$} \\
Subscripts & & \\
\hline$d:$ & Dialysate phase & \\
$r:$ & Retenetate phase &
\end{tabular}




\section{References}

[1] Alkan-Sungur, A. and Ozdural, A.R. (2009). Prediction of overall mass transfer coefficient in contiuousdialuzers: comparison of pseudo steady state approximation and unsteady state solution. Desalination, 240, pp. 64-70.

[2] Palaty, Z., Zakova, A. and Petrik, P. (2006). A simple treatment of mass transfer data in continuous dialyzer. Chemical engineering and processing, 45, pp. 806-811.

[3] Raff, M., Welsch, M., Gohl, H., Hildwein, H., Storr, M. andfWittner, B. (2003). Advanced modeling of high flux hemodialysis. Journal of membrane science, 216, pp. 1-11.

[4] Yeh, H.M., Cheng, T.W. and Chen, Y.J. (1997). Analysis of dialysis coupled with ultrafiltration in cross flow membrane modules. Journal of membrane science, 134, pp. 151162.

[5] Yeh, H.M and Chang, Y.H. (2005). Mass transfer for dialysis through parallel-flow doublepass rectangular membrane modules. Journal of membrane science, 260, pp. 1-9.

\section{بحث امكانية استخدام أغشية منخفضة التكاليف فى عملية فصل الأملاح}

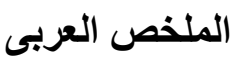

فى هذا البحث تم استخدام غشائين من مو اد تجارية مثل النايلون و البولى ايثيلين لفصل الأملاح. من التجارب التصن

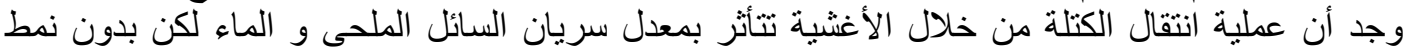

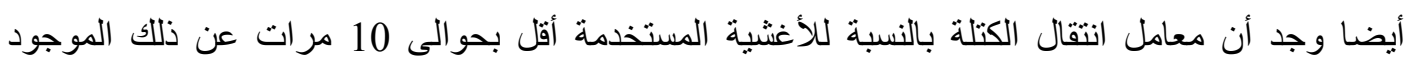
بالأبحاث المنشورة و التى تم استخدام أغشية أكثر شيو عا لمثل هذه التهال العمليات.

تم استتباط علاقة رياضية لحساب معامل انتقال الكتلة و عند مقارنة نتائجها بالنتائج المعملية وجد أن هناك تو افق بين الأثنين. 